SCHOLARS: Journal of Arts \& Humanities

Volume 2, August 2020, pp. 74-82

[Peer-Reviewed, Open Access, Indexed in NepJOL]

Print ISSN: 2773-7829; e-ISSN: 2773-7837

DOI: https://doi.org/10.3126/sjah.v2i0.35015
Central Department of English

Tribhuvan University

Kirtipur, Kathmandu, Nepal

www.cdetu.edu.np/ejournal/

Review Article

\title{
Rhetorical Situation and Academic Writing for the Master's Program in English: A Review
}

\author{
Hem Lal Pandey \\ Central Department of English \\ Tribhuvan University, Kirtipur, Nepal
}

\begin{abstract}
This paper reflects on what writing practices are taking place in the M.A. English Curriculum in Tribhuvan University. Along with some theoretical discussions on the rhetorical situation and writing process, it observes and makes a review of firsthand experience of the teachers and students' in classes of the Academic Writing course. Here, through this paper, my attempt is to bring three issues together: illustrate the objective of academic writing course implemented in the M. A. English Program; reflect on the students' real experience with it; and present some ways to help students overcome 'writer's block' while preparing different term papers and final thesis that they are required to write. Obviously, the targeted audience of my paper are the students; fellow colleagues (since I have collected genuine classroom experience of the students and my own and have presented them with a purpose) and the authorities of TU as well (because students who are required to write need support of the library, the online sources and publishing forums). As a faculty exposed in both the annual and semester systems, I have also highlighted some differences that I have observed and noticed between the goals of curriculum of annual and semester. The small size classroom, easy access to the online databases and opportunity to publish best papers, serious efforts and perseverance of the instructors and the students, regular seminars and workshops, and remedial classes on language and editing are some immediate exigencies for making students adept in academic writing. Only after meeting these requirements and the management of archival collection of students' writing to verify originality and plagiarism, we can really stimulate students' interest in writing and institutionalize the academic writing culture in the university.
\end{abstract}

Keywords: Academic writing, writing process, rhetorical situation, invention strategies, revision and editing

\section{Introduction}

Regardless of limitations of rules, a writer's journey through academic writing advances only after his or her familiarity with the conventions of writings. Toby Fulwiler, in his College Writing: A Personal Approach to Academic Writing, also claims that the realm of writing is boundless and is likely to appear in varieties of structure and styles which are neither to be exactly followed nor to be ignored: "Yes, writing is a 
Rhetorical Situation and Academic Writing for the Master's Program in English 75

complex, variable, multifaceted process that refuses foolproof formulations. Still, people have been writing since the dawn of recorded history [...] some 3,000 years, and during that time some habits and strategies have proved more helpful than others. Learning what these are may save some time, grief, energy, or perhaps all three" (16). With due acknowledgement to Fulwiler, I firmly believe that that basic principles of writing are impervious to discrete styles that the authors employ in their writings. My own personal experience tells that each time, after the end of semester classes on academic writing in the past, I struggled to write and publish on the issues of practices, problems and prospects of academic writing in classroom settings, but I was always stuck somewhere. Among several reasons, writing a paper on it impelled me to emphasize and follow something about 'foolproof formulations' and in a way go beyond them wherever they impede. I have also found the significance of such foolproof formulations to the novice students in the writing class so that they can have basics of academic writing and get into the journey through critical and creative writings. Some of those basics include rhetorical situation, documentation styles, motives of writings, ethos, logos and pathos, etc.

TU launched its semester system in a tumultuous situation. We, the faculty, expected massive changes in the previous curriculum so that English Department would be successful at catering students' interest. Accordingly, the new curriculum brought significant changes in in the curriculum, especially by introducing the course in academic writing. As envisioned in the new syllabus, the course in academic writing intends to strengthen the learners to be creative and critical in both reading and writing activities. Moreover, it aims at guiding students to produce original research papers. The expected result is to make them familiar with the writing skills. This is where Wayne C. Booth et al. argue that, through writing, the writers "join a conversation that, at its best, can help ... [them and their] community free ... [themselves] from ignorance, prejudice, misunderstanding, and the half-baked ideas that so many charlatans try to impose. . ." (11). It is through this skill that students hone their critical and creative insight that helps them to join scholarly community.

Let me briefly outline what writing courses that our students are introduced during four semesters. Among four semesters in total, two of the courses, including Academic Writing I and Academic Writing II with three credits each are in the first and third semesters, respectively. In these papers, the students are exposed to different types of writing such as descriptive, narrative, argumentative, research and informative. Different strategies and processes are introduced them concomitantly with those multifarious genres of writing. Besides these, a course in Language and Communication in the fourth semester envisages "to discover how professionals think and process information in order to communicate effectively. Through the discovery, the students will be able to tailor their communication to their desire outcomes" (vi) The course in Thesis Writing in the final semester aims to enable students "to produce research works of international standards" (x). Additionally, each student invariably produces at least a term paper in all courses in each semester. A course in Life Writing: Theory and Practice (in the third semester) demands an additional narrative writing from students to make them produce their own version of life narrative. In this paper, the students get ample exposure to varieties of life narratives including memoir writing, auto/biographical writing, diaries, journals, letters and essays. This personal narrative falls into the genre of creative writing. At the end of the semester, the students produce twenty five to thirty 
Rhetorical Situation and Academic Writing for the Master's Program in English 76

five pages long thesis in partial fulfillment of the degree. This survey of the courses reflects the fact that there are a large amount of writing requirements, which is prescribed for the semester program, which did not exist in the annual system.

\section{The Rhetoric of Writing}

The common occurrences of writing stuffs cannot be even imagined beyond the rules, structures and conventions of theory of writing and rhetoric. To be a competent member in the writing community, one needs to follow the shared principles of the community. In addition, the writing activities take place within five elements of rhetorical situation (author, audience, topic, purpose and occasion) and five fundamental steps of writing process (invention, planning, drafting and revising). In this paper, I briefly discuss what these elements and steps actually mean and what obstacles our students come across in the process and what measures we can apply so that they can redeem hindrances and bring quality in their writing. While developing this article, I reached my students with a dozen of germane questions the writing process, difficulties and their expectations from the facilitators/instructors and the institution. Here, I attempt to corroborate my arguments by locating my classroom experience along with the experience of the students from the current fourth semester group.

The nature of writing course is distinct in terms of its pedagogy as it demands relentless and incessant support of the instructors to the students. The instructors' role encompasses: topic assignment to - help them find relevant sources to - assist them to revise and edit their work. In our context, we have to grapple with rectifying the grammatical errors as hardly few students can produce grammatically correct sentences. In some cases, the task is much involved that as an instructor I am messed up in figuring out what the student means by the sentences. Rob Pope frames this rigor of the writing instructor into what he calls "the hierarchal division of labor between 'Eng[lish] Lit[erature] and 'Rhetoric and Comp[osition]"' (37). Hence, rhetoric and writing course requires huge responsibility, patience and enthusiasm from both the instructors and the students.

A bird eye view on writing related content of M. A. English Curriculum demonstrates that major task of the instructors in the classroom is to orient the students in the convention of academic writing, be it an argumentative or a personal essay. The fulfilment of this requirement demands allotment of dedicated hours of the instructors. Instructors have provided students different writing assignments and assess them in a timely manner by providing constructive feedbacks. Additionally, those writings can be refined through further revision and editing and finally publish them as academic publications. While making a survey of the students about this issue, a question "Have you published your writing?" was asked to the students, in which everyone, except a couple of them, responded "no". It clearly demonstrates, irrespective of good exposure and opportunities of writing course, a bleak picture of writing and publishing with myriads of genuine reasons such as: they do not know where to publish them; their writings do not meet the standard; they are not encouraged; they do not know the significance of writing and publishing; they do not aspire to learn and develop career in writing and publishing; etc. We, the faculty at the department often discuss about publishing the writings of the students in the departmental journal, but it has yet to be materialized. For this purpose, we need to work together to motivate the students to 
write, help them revise and edit, and make their writing publishable. So they may utilize their classroom as a forum to establish their foundation of writing career for the future, too.

\section{Rhetorical Situation and Its Practice}

Canons of rhetorical situation such as author, audience, purpose, topic and occasion work together in such a way that the composite whole becomes a communicative act between the author and the audience. In this situation, both the author and the audience involve in communication with a purpose in mind. In order for communication to happen, one needs to follow the convention of writing in the discipline. Given this situation, the writing course is a prerequisite and fundamental course for all the departments irrespective of language and literature. This is why a growing common practice in the western universities is to stretch writing and rhetoric course to "encourage writing and communication skills rooted in a whole range of departments, not just in 'English' department as such" (Pope 37). In doing so, to make the students adept in writing, we help them to broaden capacity as per the demands of national and international job markets. We can partly eschew ourselves from the charges that the universities in Nepal are educated unemployed and brain drain production sites. Because the students with good writing skills can get jobs in different fields. My personal experience with the students is worth mentioning in this context. I often start my initial classes in the first semester asking them what fascinated them to join the M. A. English Program and a couple of students report that they want to develop themselves as writers. But significant changes do not appear in their route across the fourth semester. If we are to understand this problem, we have to be self-reflexive and judgmental about our effort in classroom activities, our dedicated hours used assist students in writing term papers and theses.

Audience, as a second element of rhetorical situation, makes us to see writing in the author audience interface. It does not happen in isolation. The imperative of keeping audience in mind is to select tone, style and level of diction. While writing, we have to cast ourselves into a certain subject position to deal with the ideas and issues that we plan to develop and discuss in our writing. Regarding audience, Chaim Perelman's concept of two types of audience is pertinent for the discussion: particular audience and universal audience (14). For him, a particular audience is the immediate and specific interlocutor who resides in the mind of the author to whom the message is directed and any possible reader from the entire universe comes into universal audience. To quote him, particular audience "can be the speaker himself, reflecting privately about how to respond to a delicate situation. Or it may be all of humanity, or at least all those who are competent and reasonable - those whom I would call the 'universal audience', which may itself be made up of an infinite variety of particular audiences" (14). For instance, when my students develop narrative writing or life narratives, they keep me as an immediate interlocutor of the text. But in another situation, they produce an argumentative essay on a debated topic in which any competent and reasonable person can be its audience. Given the fact that writing is a communicative act, each writer needs to develop their writing in such a way that the intended message effectively and persuasively reaches to the audience. This is why Perelman stresses the importance of the anticipated audience's role in writing as he argues, "[i]t would be pointless for the speaker develop his 


\section{Rhetorical Situation and Academic Writing for the Master's Program in English 78}

argumentation without being concerned with the reactions of the sole interlocutor, who necessarily moves from the role of the passive listener to that of active participant" (15). Consequently, the writers need to visualize the responses of the audience and develop the text as a communicative element.

Regarding the students' perception and employment of audience factor in their writing, I have seen that most students do not take it seriously because they are naïve (and may be novice too) about it. However, some of them tend to believe that most often the instructors as audience impede their writing and lead to 'writers' block'. They also reported that the instructors appear as experts in their mind who make them lose their confidence. Since they rarely plan to publish, the universal audience barely exists in their mind. But while writing argumentative type of essay, audience's anticipation of the possible objections, questions, alternative viewpoints and acknowledgement and response to them logically and persuasively are must. Hence, active and participatory role of the audience in writing cannot be ignored and negated at all.

Text or the topic is the third tangible element of rhetorical situation. It includes a wide range of students' writings. In my experience, I invariably motivate my students to write about anything. I suggest students to write something whenever they complete reading stuffs like, a poem, a chapter of a novel, a play, an essay, a story. It works to sharpen their understanding of what they read and make interactive class in discussing ideas and details of the given topic. This technique works to make students come up with genuine questions for classroom discussion. Through this process, students not only become active readers of a text, they also do it with a purpose. This is how I help students take a topic in writing classes. Through such transaction of reading and reacting, there are greater chances of enhancing the critical thinking in reading activity.

The writers can also develop text (their writing) through different invention strategies. Some of the common strategies of finding a topic include brainstorming, freewriting, mapping, listing, journalists' questions and many others. For our classroom purpose, Kenneth Burke's theory of pentad may serve germane to generate ideas in a term paper. Particularly, this method helps students find ideas for their writing. Burke argues:

We shall use five terms as generating principle of our investigation. They are: Act, Scene, Agent, Agency, Purpose. In a rounded statement about motives, you must have some word that names the act (names what took place, in thought or deed), and another that names the scene (the background of the act, the situation in which it occurred); also, you must indicate what person or kind of person (agent) performed the act, what means or instruments he used (agency), and the purpose. (xv)

Personally speaking, I have found the invention strategy of pentad significantly useful while making students write an analytical paper on a short story, a novel or a play. Through this technique, they may have to bring together different aspects of a text. Burke uses an analogy of these elements to a hand with five separate fingers, where fingers stand separate but ultimately connected and integrated to each other. A student can choose a story and see how its setting, the environment, the locale, the landscape, atmosphere and time (all constitutive of Burke's scene) is an integral part of the purpose of characters doing something. Moreover, the student can stretch it to the analysis of what is done (act), who is involved in it (agent) and by what means the act is 
Rhetorical Situation and Academic Writing for the Master's Program in English 79

accomplished (agency). This is one example of how writing can be a tool to have critical, comprehensive and effective close reading strategy of a text.

Beyond the use of invention strategies, the writers often use reading as a tool to generate ideas for their papers. Extensive reading of reviews, journal articles, books, etc. helps the students to develop ideas for their writing assignment. However, students and faculty become helpless with lack of access to the reliable and scholarly database sources readily in the department itself. Demanding 'scholarly' writing without providing sources is ludicrous. In a question: 'how do you manage sources for your writing?', many students reported that they 'run here and there' including the TU Central Library and Social Science Baha. They earnestly demand this facility available at computer lab of the department itself. Having said this, departments have to provide online databases like JSTOR, ArticleFirst, FirstSearch, ebscohost, and others so that students get materials to understand the text that they study and support their arguments with scholarly ideas while writing on it. For online books, they can use the online electronic libraries like en.bookfi.net and Library Genesis (gen.lib.rus.ec). This access provided by the department may help students explore reading materials for writing.

The writers have reason to write and there are multifarious purposes (fourth element of the rhetorical situation) embedded in each and every piece of writing. Robert Keith Miller and Suzanne S. Webb's categorization of writings under ten types seem useful to understand the purposes of writing: writing to record a memory, writing to discover oneself, writing to amuse others, writing to move others, writing to persuade others, writing to convey information, writing to explain something, writing to evaluate something, writing to explore an idea and writing to understand reading. Based on these purposes, the authors have entitled their book as 'motives for writing'. Having said this, we are to understand the fact that each piece of writing predominantly focuses on one among the three rhetorical situations: author, audience and the text. Robert Keith Miller and Suzanne S. Webb tend to classify writings based on where the focus lies:

Recording a memory and discovering oneself focus mainly on satisfying the needs of the writer. Amusing, moving, and persuading others focus mainly on eliciting an appropriate response from the audience. Conveying information, explaining something, evaluating something, exploring ideas, and writing about reading focus on varying degrees on the subject matter or topic. (2)

Students are required to have basic theoretical knowledge of these divisions in the first semester so that they could compose writings that meet the convention of academic writing with varieties. They are found producing writing on recording a memory (under narrative essays in Academic Writing and Life Writing), discovering oneself (under personal public argument and different writings on the course in Language and Communication), persuade others (under argumentative essay) and explore an idea (in different term papers and thesis writing). It seems that our students get abundant opportunities to get familiar with diverse types of writings. If they are taken them seriously, they will be really adept in writing.

The fifth element to examine in this rhetorical situation is occasion. It may sound equivocal, but occasion means where and when writing takes place and it implies constraints and requirements. For our classroom purposes, the students mainly produce writings under the assigned topics in which they are expected to use appropriate tone and 
diction. Moreover, each form of writing has its own convention, they need to follow the MLA documentation styles, follow research ethics and mechanics, revise and edit and keep the papers free from copy paste culture (plagiarism). Maintaining ethics is not only essential but also a prerequisite in academic writing. For their comfort, the researchers should not distort or misrepresent the original source's meaning or essence. Accordingly, the cited language in writing should be as it is of the original source. It also needs to maintain in the paraphrased language as well. For ethics, Wayne C. Booth and others imply the following suggestions for the researchers:

- Ethical researchers do not plagiarize or claim credit for the results of others.

- They do not misreport sources, invent data, or fake results.

- They do not submit data whose accuracy they don't trust, unless they say so.

- They do not conceal objections that they cannot rebut.

- They do not caricature or distort opposing views.

- They do not destroy data or conceal sources important for those who follow. (274)

The revision strategies and organization structure also constitute occasion in writing. Each genre has its own convention of organization of idea. For instance, a letter begins with the recipient's address and ends with valediction whereas a fairy tale begins with "once upon a time..." and ends with 'they/he lived happily forever'. Official writings and research reports demand formal diction and casual conversation in a narrative that is in informal diction. Following the standard of generic convention is also to meet the occasion in writing.

\section{Revision Strategies in Writing}

Regarding the revision strategies, mostly the sources suggest to follow three tools: addition, deletion and reorganization. Through revision, unclear, vague and controversial ideas need to be rectified with additional ideas, repeated ideas need to be omitted and related ideas are to be grouped together. Needless to say that one needs to maintain his or her best for precision, correctness and accuracy. The use of varying length of the sentences and varying sentence structure, active voice supplanting the passive, removing clichés, jargons and redundancies are some other common guidelines provided in the process-based writing strategies. After revising, typos, grammar and punctuation errors are rectified at the end of the writing process. Indeed, all these activities cannot closely be monitored in a large size classroom. The writing class needs to be transformed into a workshop class within 15-20 students. For revision, the students are found excited to work in groups and develop a peer review culture. M. Garrett Bauman, in Ideas and Details: A Guide to College Writing, which is prescribed in the first semester, provides guidelines for peer review strategies and, if taken seriously, it helps them to learn from collaborative activities. In a survey about the revision experience of the students, it is reported that they do not revise until they get feedback from the instructors. Interestingly, almost all admitted that their first draft itself becomes the final if the instructors do not get paper returned. Here, the concept process-based writing seems dysfunctional.

Plagiarism has also been found rampant that has become incorrigible habit of students. As a faculty, I have to admit that even if I assign a topic along with clear 
Rhetorical Situation and Academic Writing for the Master's Program in English 81

writing guidelines, more than ninety percent of my students plagiarize from Wikipedia and Google in their first draft. It badly disappoints me. It bears several reasons such as: writing is a difficult task for those students who barely write except final year exams; it needs time and effort which many students mostly do not like to invest; they do not have habit of writing; they are not habituated with mechanics of writing and documentation styles; all faculty do not take it seriously; the instructor cannot expel the students from the program; the gap between students and instructors is still extant in the semester-based learning practice. All these reasons are found in the students' response to the question: what encourages you to borrow ideas from unacknowledged sources, if any?

To mitigate the intensity of plagiarism, the university should develop a policy in which the faculty should be empowered with full-fledged authority to penalize and expel (in extreme cases) the students. But in current practices, the authorities seem reluctant for all these 'academic troubles'. To avoid plagiarism in writing, the originality detection software should be used by both the faculty and students. If each department has this software to detect plagiarism, then both the faculty and students can build confidence in writing. Otherwise faculty members have no choices but complacently approve even a thoroughly plagiarized document. The faculty and authorities should work together to materialize such things to happen in the universities. These changes can happen only when, as Iswari Pandey rightly observes the current apathy of the authorities to improve research activities and teaching learning practices, emphasizing that "the core guiding principle [of the university] must be an unfettered pursuit of knowledge" (58). His apothegmatic remark about the university sounds sardonic because no scholars need to discuss what universities are for.

\section{Conclusion}

To conclude, the learning outcome of the course like the M.A. English Program can be materialized through the writing courses. Writing, here, should be kept free from the parochial understanding of it as a mere medium of expressing what we have in our mind. Rather it should be taken as a highly productive tool to be an active learner both in classroom and beyond. It is simultaneously a way to be critical and creative in the teaching learning activities. As the students participate in the discussion in the classroom situation, their perception is ignited and sharpened only when they write and reflect over the issues that they study and discuss. Amidst the bleak situation of massive decline of students' enrolment in English Department, we can have a scant hope that the revival may take place through the course in Rhetoric and Writing.

\section{Works Cited}

Axelrod, B. Rise, and Cooper, R. Charles. The St. Martin's Guide to Writing. The St. Martin's Press, 1991.

Ballenger, Bruss. The Curious Writer. Longman, 2005.

Bauman, M. Garrett. Ideas and Details: A Guide to College Writing. Wadsworth, 2007.

Biggam, John. Succeeding with your Master's Dissertation: A Step-by-Step Handbook. Open UP, 2011.

Booth, C. Wayne, et al. The Craft of Research. The U of Chicago P, 2008.

Fulwiler, Toby. College Writing: A Personal Approach to Academic Writing. Cook Publishers, 2002. 
Rhetorical Situation and Academic Writing for the Master's Program in English 82

M.A. English Curriculum. Dean's Office, Faculty of Humanities and Social Sciences, Tribhuvan University, 2015.

MLA Handbook. The Modern Language Association of America, 2016.

Miller, Robert Keith, and Suzanne S. Webb, editors. Motives for Writing. Mayfield Publishing Company, 1992.

Pandey, Iswari. "Means and Ends: How to Use Semester System to Transform a University

Education." TU Bulletin Special 2019. Tribhuvan University, pp. 57-65.

Perelman, Chaim. The Realm of Rhetoric. U of Notre Dame P, 1982.

Pope, Rob. English Studies: An Introduction to English Language, Literature and Culture. Routledge, 2010. 